\section{Does science serve the wildlife industry? A critique of von Brandis \& Reilly (2008)}

\author{
${ }^{\ddagger}$ P.J. Nico de Bruyn', Marietjie Landman', \\ Craig J. Tambling $^{1 *} \&$ Luke Verburgt ${ }^{3}$ \\ ${ }^{1}$ Mammal Research Institute, Department of Zoology and \\ Entomology, University of Pretoria, Pretoria \\ ${ }^{2}$ Centre for African Conservation Ecology, Department of Zoology, \\ Nelson Mandela Metropolitan University, Port Elizabeth \\ ${ }^{3}$ Department of Zoology and Entomology, University of Pretoria, \\ Pretoria \\ Received 28 August 2008. Accepted 9 November 2008
}

Throughout the world, terrestrial mammals are hunted for sport, subsistence and population control, providing a significant source of meat and income to communities (Milner et al. 2007). The game ranching industry in South Africa relies heavily on trophy hunting as a primary source of income (du Toit \& van Rooyan 2002), and hence may be subject to manipulation that could increase revenue. The industry is growing rapidly, and steps need to be taken to ensure that this industry is sustainable, and is firmly grounded in science with effective government policy. In a recent article in South African Journal of Wildlife Research, von Brandis \& Reilly (2008, hereafter vB\&R) claim that significant spatial variation exist in the trophy quality (a function of horn size) of ungulates in South Africa and advocate the importance of a national trophy quality monitoring programme in order to control potential manipulation of trophy populations.

vB\&R raise concerns over the extent of artificial selection being applied in the wildlife industry (see also von Brandis \& Reilly 2007). Although these are important concerns within the game industry that require attention, there are philosophical and methodological limitations of this study that question its conclusions. Here we critically assess the analytical approach and the conclusions of that study.

\section{Data and analysis irregularities}

The purpose of calculating an entire Safari Club International (SCl) score for 5300 trophies to compare to the dataset of Rowland Ward (RW)-

${ }^{\ddagger}$ Authors in alphabetical order and all authors contributed equally.

*To whom correspondence should be addressed.

E-mail: cjtambling@zoology.up.ac.za measured horns, is unclear since both methods include a seemingly similar measure of the 'longest horn'. Nevertheless, there remains the need for the analysis regarding database pooling of the full $\mathrm{SCl}$ score and RW to be conducted correctly and presented in its entirety. No mention was made of the type of correlation test undertaken, and no statistics of this analysis were presented. The same analysis was conducted on 20 different species yet no correction for Type I errors (e.g. Bonferroni correction - Rice 1989) due to multiple tests were employed. It should be noted that three of the 20 species used in the analysis have undergone name changes (blesbok is not Damaliscus dorcas but Damaliscus pygargus phillipsi, bontebok is not Damaliscus dorcas but Damaliscus pygargus pygargus, eland is not Taurotragus oryx but Tragelaphus oryx) prior to the study being submitted for publication (Skinner \& Chimimba 2005).

There is additional concern that the data are not representative of each of the provinces to test a population level phenomenon. It is expected that since the taxidermists from whom data were collected are all located in Gauteng, that there would be an over-representation of trophies from nearby regions. Nevertheless, no data for either Gauteng or Mpumalanga province were presented. In the case where small sample sizes are used it is imperative that the limitations of the conclusions are discussed.

A major concern with the analysis applied in this study (and thus the conclusions) is how the ANOVA (analysis of variance) calculations were handled and interpreted as several irregular procedures for this type of analysis was found. As with the correlation tests mentioned above, no attempt was made to correct for Type I errors. We performed the required sequential Bonferroni correction on the statistics provided and show that two of the six results are indeed non-significant after correct statistical procedure is followed (Table 1). From the reported and calculated $P$-values (Table 1) there are irregularities in the reporting of at least one of the results (greater kudu: the $P$-value of $<0.01$ should have been $<0.001$ for the given $F$-value and the degrees of freedom) and in this case either the $P$-value or the $F$-statistic reported is incorrect. From the degrees of freedom of the F-statistic reported for the impala and the springbok $(8,1721$ and 8,1174 , respectively; Table 1), data for nine provinces are expected (Sokal \& Rohlf 1981; Quinn \& Keough 2002) yet only data for seven provinces are presented in 
Table 1. Sequential Bonferroni correction applied to the ANOVA results presented in von Brandis \& Reilly (2008) indicating that two of the significant results reported would have been non-significant following correct statistical procedure. Overall $N$ is the total sample size per species calculated from the degrees of freedom as d.f. . $_{2}+$ d.f. $_{1}+1$. The calculated $P$-value is calculated from the $F$-statistic and the degrees of freedom (d.f. . $_{1}$ d.f. . $_{2}$ ) using the $F$-distribution. The correction factor is the number of tests remaining in the set of tests as one evaluates each test sequentially, moving down from most- to least significant (this analysis was performed on only 14 species). The Bonferroni $P$ is calculated as the significance level $(\alpha$; in this case 0.05$)$ divided by the correction factor. In order for a test to remain significant the calculated $P$-value must be less than the Bonferroni $P$-value.

\begin{tabular}{|c|c|c|c|c|c|c|c|c|c|}
\hline Species & $F$ & d.f. ${ }_{1}$ & d.f. $_{2}$ & $\begin{array}{l}\text { Overall } \\
\quad N\end{array}$ & $\begin{array}{l}\text { Reported } \\
P\end{array}$ & $\begin{array}{l}\text { Calculated } \\
P\end{array}$ & $\begin{array}{l}\text { Correction } \\
\text { factor }\end{array}$ & $\begin{array}{l}\text { Bonferroni } \\
\quad P\end{array}$ & Significant \\
\hline $\begin{array}{l}\text { Greater kudu } \\
\text { (Tragelaphus strepsiceros) }\end{array}$ & 5.94 & 6 & 324 & 331 & $<0.01$ & 0.00001 & 14 & 0.0036 & Yes \\
\hline $\begin{array}{l}\text { Mountain reedbuck } \\
\text { (Redunca fulvorufula) }\end{array}$ & 5.48 & 6 & 189 & 196 & $<0.001$ & 0.00003 & 13 & 0.0038 & Yes \\
\hline $\begin{array}{l}\text { Impala } \\
\text { (Aepyceros melampus) }\end{array}$ & 4.06 & 8 & 1721 & 1730 & $<0.001$ & 0.00008 & 12 & 0.0042 & Yes \\
\hline $\begin{array}{l}\text { Springbok } \\
\text { (Antidorcas marsupialis) }\end{array}$ & 3.12 & 8 & 1174 & 1183 & $<0.01$ & 0.00171 & 11 & 0.0045 & Yes \\
\hline $\begin{array}{l}\text { Blesbok } \\
\text { (Damaliscus pygargus phillipsi) }\end{array}$ & 2.64 & 6 & 513 & 520 & $<0.05$ & 0.01569 & 10 & 0.005 & No \\
\hline $\begin{array}{l}\text { Eland } \\
\text { (Tragelaphus oryx) }\end{array}$ & 2.82 & 5 & 141 & 147 & $<0.05$ & 0.01851 & 9 & 0.0056 & No \\
\hline
\end{tabular}

Figs 3 \& 6 (vB\&R), respectively. Similarly, for greater kudu and mountain reedbuck (d.f. $=6,324$ and 6,189 ) data for seven provinces are expected yet only data for six provinces are presented in Figs 4 \& 5 (vB\&R), respectively. It is not clear whether zero values presented refer to the complete absence of data or the absence of trophies in that particular province.

Nowhere do the authors provide sample sizes for each of the provinces. Moreover, the similarity between the mean 'longest horn' measurement for impala of the KwaZulu-Natal province and the national mean, despite the fact that data presented from all other provinces had mean values well above the national mean (Fig. 3, vB\&R), suggests a large over-representation of samples from the KwaZulu-Natal province which may have biased the analysis. Furthermore, the large $95 \%$ confidence intervals around most of the samples from the Western Cape and many of the Free State samples suggests small sample sizes for these provinces, which may be indicative of samples acquired from Gauteng taxidermists. Although the authors stress an unbiased sampling regime, we suggest that even with no hard lower limit of trophy quality such as with the RW database, that a truncated rightskewed data distribution would exist for trophies sent to taxidermists because fewer low- to mediumquality trophies are likely to make acceptable trophies. Non-parametric tests would be required to analyse such data. However, if we are to assume that each of the data groups are indeed normally distributed per species, then one may gauge the variance of each group by observing the $95 \%$ confidence interval around the mean values shown in Figs 1-6 (vB\&R). One cannot calculate the exact variance of each group since group sample sizes were not provided. Nevertheless, it appears that the variance (as gauged from 95\% $\mathrm{Cl}$ ) is unlikely to be homogenous between provinces (e.g. very wide $95 \% \mathrm{Cl}$ for Western Cape impala compared to Northern Province impala). Large heterogeneity within the variances coupled with uneven sample sizes is considered the worst case in terms of the violation of assumptions in ANOVA calculations (Lix et al. 1996; Quinn \& Keough 2002).

No post-hoc tests were performed to determine which province(s) were contributing to the spatial variation in 'longest horn'. The authors do not mention the treatment of statistical outliers due to malformed horns (e.g. eland) or injury, or possible differences in sex when both sexes have horns (e.g. springbok, wildebeest and eland).

Finally, the effect of temporal variation on trophy quality is not addressed in the study, even though the database spans nine years. However, in a previous paper (von Brandis \& Reilly 2007), not 
cited in vB\&R, the authors show some temporal trends in some of the species and in some provinces for all species combined using the same dataset (see von Brandis \& Reilly 2007: 153). Using the same database, vB\&R pool trophy quality across time; this is only possible if no temporal trend in trophy size exists. However, since they previously did show significant temporal trends in trophy quality for some of the species (von Brandis \& Reilly 2007), this pooling of data is invalid. The two questions of temporal and regional variation in trophy size should be investigated concurrently in a single analysis

\section{Concluding remarks}

Despite the limited spatial representation of the data and the flawed nature of the analysis shown above, vB\&R conclude that there exists manipulation of trophy quality without considering any alternative hypotheses. In this regard the authors ignore and do not discuss the vast literature on intra-population variation in morphology (eg: Festa-Bianchet et al. 2004), the fact that some populations are extralimital, as well as the theoretical and empirical papers (e.g. Coltman et al. 2003; Allendorf et al. 2008) on the effects of hunting on phenotypic and genetic variation within species. Additionally, few of the references were from the peer-reviewed literature.

The analysed dataset is valuable and should be used to investigate the questions addressed in both the current paper and the previous investigation into temporal patterns (von Brandis \& Reilly 2007). However, the conclusions of the vB\&R paper should be treated with caution due to the flawed nature of the analysis. The authors argue in their discussion that '...it is perhaps more plausible to assume that the foremost cause of these variations or lack of variation is human manipulation.' We believe that this argument invalidates the necessity of the analysis performed because it can be stated regardless of the outcome of the statistics. There is a void of empirical research based on the hunting of African ungulates in the literature, and a proper treatment of the topic using this database will be of immense value for managers and scientists alike. We believe that the hunting industry needs to focus less on popular articles and more on peer reviewed scientific articles. The current journal should continue to strive to publish highquality science in the interests of the industry and its sustainability.

\section{References}

ALLENDORF, F.W., ENGLAND, P.R., LUIKERT, G., RITCHIE, P. A. \& RYMAN, N. 2008. Genetic effects of harvest on wild animal populations. TREE 23: 327-337.

COLTMAN, D.W., O'DONOGHUE, P., JORGENSON, J.T., HOGG, J.T., STROBECK, C. \& FESTABIANCHET, M. 2003. Undesirable evolutionary consequences of trophy hunting. Nature 426: 655-658.

DU TOIT, J.G. \& VAN ROOYAN, J. 2002. Hunting. In: J. du. P. Bothma (Eds), Game Ranch Management. van Schaik Publishers, Pretoria.

FESTA-BIANCHET, M., COLTMAN, D.W., TURELLI, L. \& JORGENSON, J.T. 2004. Relative allocation to horn and body growth in bighorn rams varies with resource availability. Behav. Ecol. 15: 305-312.

LIX, L.M., KESELMAN, J.C. \& KESELMAN, H.J. 1996. Consequences of assumption violations revisited: a quantitative review of alternatives to the one-way Analysis of Variance $F$ test. Rev. Educ. Res. 66: 579-619.

MILNER, J.M., NILSEN, E.B. \& ANDREASSEN, H.P. 2007. Demographic side effects of selective hunting in ungulates and carnivores. Conserv. Biol. 21: 36-47.

QUINN, G.P. \& KEOUGH, M.J. 2002. Experimental design and data analysis for biologists, Cambridge University Press, Cambridge.

RICE, W.R. 1989. Analyzing tables of statistical tests. Evolution 43: 223-225.

SKINNER, J.D. \& CHIMIMBA, C.T. 2005. The Mammals of the southern African subregion, Cambridge University Press, Cambridge.

SOKAL, R.R. \& ROHLF, P.H.A. 1981. Biometry. Freeman \& Co., San Francisco.

VON BRANDIS, R.G. \& REILLY, B.K. 2007. A temporal analysis of trophy quality in South Africa: has trophy quality changed over time? S. Afr. J. Wildl. Res. 37: 153-158.

VON BRANDIS, R.G. \& REILLY, B.K. 2008. Spatial variation in trophy quality of popular hunted ungulate species in South Africa. S. Afr. J. Wildl. Res. 38: 17-21. 